\title{
Workplace discrimination for persons with hearing loss: Before and after the 2008 ADA Amendments Act
}

\author{
Brian T. McMahon ${ }^{\mathrm{a}, *}$, James M. Grover ${ }^{\mathrm{b}}$, Megan C. McMahon ${ }^{\mathrm{c}}$ and Jeong Han Kim ${ }^{\mathrm{d}}$ \\ ${ }^{a}$ Department of Rehabilitation and Mental Health Counseling, Virginia Commonwealth University, \\ Richmond, VA, USA \\ ${ }^{\mathrm{b}}$ School of Counseling, Human Performance, and Rehabilitation, University of Arkansas Little Rock, \\ Little Rock, AR, USA \\ ${ }^{\mathrm{c}}$ Department of Psychology, University of Texas, Austin, TX, USA \\ ${ }^{\mathrm{d}}$ Department of Clinical Counseling and Mental Health, Jeong Han Kim, Texas Tech University \\ Health Science Center, Lubbock, TX, USA
}

Received 10 July 2019

Accepted 27 September 2019

\begin{abstract}
.
BACKGROUND: Individuals with hearing loss experience unique barriers to employment frequently documented in the areas of communication and education. The purpose of this article is to contribute to extend this inquiry to the uniqueness of workplace discrimination involving persons with hearing loss.

OBJECTIVE: This study investigated differences in allegations of workplace discrimination filed by persons with hearing loss ("Hearing") compared to those filed by persons with other physical or neurological disabilities (General Disability, or "GENDIS") before and after the enactment of the 2008 Americans with Disabilities Act Amendments Act (2008 Amendments).

METHODS: Using secondary data collected from the Equal Employment Opportunity Commission (EEOC) Integrated Mission System, we employ simple measures of proportion and odds ratios to describe differences between allegations derived from GENDIS and Hearing loss populations. These are population statistics, and not samples, of all allegations of discrimination reported to the EEOC through 2016. The comparisons involve Characteristics of the Charging Parties, Issues or discriminatory behaviors alleged, and closure statuses or Merit Rate of the EEOC's investigations - both before and after the 2008 Amendments.

RESULTS: Following the 2008 Amendments, Charging Parties changed dramatically on age and gender status. Reasonable Accommodation, Hiring, Harassment, and employment Terms and Conditions showed unique features between groups and/or time periods. The "veracity" (confirmed truthfulness or merit) of the EEOC allegation (or Merit) rate also changed following the Amendments: higher for GENDIS; lower for Hearing.

CONCLUSIONS: Possible rationale for these findings are offered, and new research questions are raised. Finally, implications for the cross-disability movement are presented.
\end{abstract}

Keywords: Employment, disabilities, deafness, discrimination

*Address for correspondence: Brian T. McMahon, Department of Rehabilitation Counseling, Virginia Commonwealth University,
P.O. Box 980330, Richmond, VA 23298-0330, USA. Tel.: +1 (804) 240 4587; E-mail: btmcmaho@vcu.edu. 


\section{Hearing loss and employment overview}

\subsection{Three case studies}

Consider the challenges for the following individuals with hearing loss who experienced real-world discrimination in the workplace due to varying levels of hearing loss.

1. In 2009, charges were brought against a coal producer in Alabama for refusing to accommodate a hard of hearing mineworker. The worker was transferred to a different mine within the company, where his hearing aids were damaged by damp conditions and electromagnetic interference. With poor amplification, the worker experienced a higher risk of accident or injury. Accommodations provided him at the first mine were then refused [1].

2. In 2010 , a completely deaf pet groomer with 30 years of experience received a $\$ 145,000$ settlement in a lawsuit by the Equal Employment Opportunity Commission (EEOC). A large Colorado company had long communicated with the worker using sign language and also provided assistance on the telephone to schedule her appointments. A new manager, however, refused to provide the latter accommodation, and even informed callers that the worker was no longer employed there. Her loyal customer base was referred to other non-disabled workers [2].

3. In 2010, the EEOC sued an assisted living facility for refusing to accept the services of a temporary, "hearing-impaired" certified nursing assistant (CNA) to help cover an evening shift. The temporary staffing agency scheduled her services at the request of the facility for qualified help; but she was told she could not work the scheduled shift due to her hearing loss [3].

\subsection{People with hearing loss}

The term "hearing impairment" has been used (a) to broadly describe hearing loss at any and all levels, from mild to profound, and also(b) interchangeably with the term "hearing loss." [4] When the terms "hearing impaired" and "deaf" are occasionally used together, they suggest a community or likeness different, but of similar condition. It should be mentioned that in some communities of persons with hearing loss, primarily among the "capital-D Deaf", the term "hearing impaired" is seen as offensive and avoided.[5]

The prevalence of self-reported hearing trouble without a hearing aid in the United States was at nearly $17 \%$ of adults over 18 years of age in 2014.[6] According to its Survey of Income and Program Participation (SIPP), the US Bureau of the Census, found about 7.6 million people aged 15 years and older had "difficulty hearing," defined as, "experiencing deafness or having difficulty hearing a normal conversation, even when wearing a hearing aid.” [7](p.8) These numbers amount to about 1.1 million people with "severe" hearing loss (i.e., deaf or unable to hear a normal conversation), and about 6.5 million with loss characterized as "not severe", as defined, but severe enough to constitute difficulty hearing even with a hearing aid. All sources indicate that hearing loss is more prevalent among persons age 65 and over.

\subsection{To be deaf: Two populations}

According to the World Health Organization [8], to be "deaf" is to have a hearing loss so profound as to have little to no functional hearing, meaning that they are unable to process speech and language through hearing. They further suggest "Deaf people... often use sign language for communication.”(p.1) While some persons who are deaf do indeed use sign language, it is also true that individuals who have this degree of hearing loss may have acquired it as adults [9], and would not likely have learned sign language. These individuals "... face substantially different adjustment challenges than those who became deaf during childhood. Many late deafened persons must relearn various ways of coping in their everyday lives." [9](p.5).

The "Deaf" then may comprise two distinct groups, functionally and culturally, whose only similarity may be that of a diagnosed and significant hearing loss. These distinctions must be considered with the caveat that, from individual to individual, people with hearing loss may vary considerably in their social or cultural affiliation, and identify with more than one population in terms of degree and type of hearing loss, communication and/or social preference.[10] For example, one who is culturally Deaf may have a capacity for speech sufficient to mix in professional or social settings with hearing people; likewise a person who is functionally hard of hearing may use American Sign Language and socialize as an 
accepted member of the Deaf community - as indeed may a hearing person within a Deaf family.[10] Still, assuming some overlap from individual to individual, general group descriptions are helpful to discussion in this paper, in identifying common characteristics and barriers to and in employment.

Primarily, the culturally Deaf are a people whose main unifying distinction is a common language, i.e., American Sign Language. As is true of any culture group, there are also distinctive mores, attitudes, and values peculiar to this population emanating from a reliance on vision to interact and communicate.[11] Persons who are late-deafened, on the other hand, will have acquired a significant hearing loss after the acquisition of language.[12] Distinct from persons who are culturally Deaf, who have a language and community that largely negates the need for spoken communication [13], persons who are late-deafened see their loss as a disability. To them, the loss usually presents as a significant communication barrier with a devastating effect on lifestyle, family, social affiliation, and status in the community, a constant reminder of separation from all they know.[14-16] For these individuals, deafness may be perceived an interminable problem, something to overcome in an effort to remain part of their "hearing" community.[16]

\subsection{To be hard of hearing}

The term "hard of hearing" is more colloquial than technical. Luft [17] defined the term as: "individuals with a hearing loss of $70 \mathrm{~dB}$ or greater are considered 'deaf,' whereas those with more hearing are labeled "hard of hearing."' (p. 52) The term "dB" refers to "decibels," a unit of measure of the intensity or loudness of sound recorded on an audiogram.[18] Watson et al. [9] defined "hard of hearing" more practically, if vaguely, as "a hearing impairment resulting in a functional loss, but not to the extent that the individual must depend primarily upon visual communication." (p. 6) Its definition may therefore vary based as much on the individual's perception and management of the loss [19], as on the measured intensity and/or frequency necessary to hear [20.] The term may be understood to mean a hearing loss short of deafness, in which residual hearing is sufficient for communication, with or without the support of assistive listening devices such as hearing aids.

\subsection{Employment and barriers for persons with hearing loss}

Persons with hearing loss generally fare better in the labor market than those with other types of disability. Disability Statistics [21] reported that $36.2 \%$ of U.S. non-institutionalized persons with disabilities, ages 21-64, were employed in 2016. In the same year, $52 \%$ of non-institutionalized persons with hearing loss, ages of 21-64, were employed. If this appears impressive, it is noted that $75 \%$ of persons without disabilities were employed the same year. The 2010 National Longitudinal Transition Study-2 (NLTS2) reported similar results for young people with hearing loss transitioning from high school [22]. A much higher rate was reported for young adults with hearing loss (64\%) when compared to those with "orthopedic impairments" (38\%) or "visual impairments" (40\%). Young adults with hearing loss attended postsecondary schools' rate of $71 \%$, compared to those with autism (47\%), emotional disturbances (45\%), multiple disabilities $(31 \%)$, or mental retardation (28\%) [23]. It remains clear that barriers to and in employment, whether in hiring or retention, are still considerable for persons with hearing loss [24].

Capella [25] found that deaf and hard of hearing workers were more likely to be employed in clerical and administrative support and less likely to be employed in service occupations than those with other disabilities. Only 19\% of clients held professional, managerial, and technical jobs. Other studies $[17,26]$ suggest that workers who are deaf engage more non-professional occupations, whereas those workers who are hard of hearing hold more professional occupations [27-30]. Haynes [31] concluded that this is likely due to the difference in verbal communication ability and requirements, which affect both employment acquisition and job advancement.

Common barriers to employment are varied, but often involve communication and educational preparation. Haynes [31], Houston et al. [26], and Luft [17] emphasized the obvious problem of communication difficulties wherever verbal communication is typically expected or required, e.g., with coworkers, supervisors, and customers [32, 33]. A subtler communication impact exists in their inability to participate in social interaction in work settings [17]. Missing informal yet important information may also limit one's ability to perform the job as well as possible $[17,32,34]$. 
Luft [35] and Luft and Huff [36] further discussed the impact of poor academic skills of children with hearing loss in transition, especially those who are Deaf as opposed to hard of hearing. Deaf students tend to graduate, or otherwise leave, high school with a reading level of approximately the fourth grade, a rate that has not appreciably improved throughout the 20th century [37]. Literacy tends to be inversely related to the level of hearing loss [35]. Persons with less severe hearing loss are more likely to achieve reading levels above fourth grade, but those with moderate to severe hearing loss achieve these higher reading levels only $46 \%$ of the time [35]. As might be expected, poor academic achievement has also been associated with poor graduation rates among students who are both deaf and hard of hearing [35, 38].

Additional barriers to employment include conflicts due to a lack of understanding of Deaf culture by the employer [39] and inadequate understanding by the worker of legal rights and appropriate accommodations, as documented by Bowe et al. [40], Houston et al. [26], and McCrone [41].

\section{The original ADA, Amendments, and hearing loss}

The Americans with Disabilities Act (ADA) of 1990 is an historic piece of legislation for people with disabilities [42, 43]. ADA Title I is a unique civil rights statute in that its purpose is anti-discrimination, not affirmative action. ADA Title I holds that all personnel consequences be unrelated to the existence or consequence of disability. It further holds that all personnel actions are subject to reasonable accommodation when the individual with disability is qualified. The ADA defines a "qualified individual" as a person with a physical or mental impairment that "substantially limits" one or more "major life activities." As "hearing" was identified as a "major life activity", persons with hearing loss are a protected group.

\subsection{How the Amendments came about}

After ADA passage in 1990, the courts struggled with a consistent interpretation of the basic definition of "disability." Nine years after passage, a series of Supreme Court decisions, collectively referred to asthe Sutton Trilogy, narrowed the definition, and by extension the number of people protected by the law in ways that Congress never intended [44]. The Court ruled that mitigating measures - medication, prosthetics, hearing aids, other auxiliary devices, diet and exercise, or any other treatment - must be considered when determining disability status [45]. Suddenly people with serious health conditions who were fortunate enough to find an effective treatment - and more able to work - often found that they were not protected by the ADA at all. Then, in 2002, the Supreme Court stated that courts should interpret the definition of disability narrowly in order to create a demanding standard for qualifying as disabled. An employer may say a person is "too disabled" to do the job but "not disabled enough" to be protected by the law. The scope of the ADA suddenly tapered such that both litigation and formal complaint activity plummeted after 2000 [46-48].

A new 2008 Amendments Act began to take form in 2007. A bipartisan U.S. Congress was supportive of passage due its concern over judicial activism. The negotiations between business and disability principals were intense and unprecedented. At the end of the day, the House of Representatives passed the bill $402-17$, followed by unanimous consent in the Senate (remarkable in an era of extreme partisanship). President George W. Bush signed the 2008 Amendments Act on October 19, 2008 and it became effective on January 1, 2009.

\subsection{The net effect of the Amendments}

Although the 2008 Amendments continue to define disability as a physical or mental impairment that substantially limits a major life activity, the Amendments dramatically expanded the range of people protected just as Congress originally intended. The 2008 Amendments direct Courts and the EEOC away from a focus upon this question: "Is the Charging Party a person with a disability?" The preferred question is: "Did a discriminatory event occur?" This shift in focus is more consistent with the "anti-discrimination" intent of the ADA, which is a remedial statute intended to rectify many decades of willful discrimination. For a more thorough description of significant changes to the ADA enacted by the Amendments Act, see Rozalski et al. [44] and McMahon [49].

\subsection{The 2008 Amendments and hearing loss}

The National EEOC Research Project (NEARP) uses data collected by the EEOC to document the 
nature and scope of workplace discrimination involving disability. Since its inception in 2003, NEARP has obtained data on 834,536 closed allegations spanning from the effective date of Title I in 1992 through 2016 [50].

The purpose of this article is to update a classic NEARP article by Bowe et al. [40] which described the uniqueness of workplace discrimination involving deafness and hearing loss. The present study replicates Bowe et al.'s work with two important exceptions. First, the data involved herein include a much longer study period of 24 years. The cohort of Hearing (individuals who are deaf, hard of hearing, or have some other hearing loss) allegations has grown by $150 \%$ to 21,847 , and the comparison cohort (general disability, or "GENDIS") has grown by $105 \%$ to 339,795 . Second, this study proposes a novel research objective, which is to document the differences in discrimination before and after the effective date of the 2008 Amendments, January 1, 2009.

\section{Research questions, study design and methods}

\subsection{Research questions}

1. When allegations derived from GENDIS are compared to those derived from Hearing, how are they different with respect to Charging Party Characteristics, core Issues alleged in the complaints, and the Merit status of the investigations when they are closed and resolved?

2. When allegations derived from GENDIS are compared to those derived from Hearing, what changes occurred following the 2008 Amendments (January 1, 2009) with respect to Charging Party Characteristics, core Issues alleged in the complaints, and the Merit status of the investigations when they are closed and resolved?

\subsection{EEOC and NEARP procedures: Collection and construction of the study dataset}

The EEOC is the federal agency created by the Civil Rights Act of 1964. Consisting of approximately 2,000 attorneys, mediators, and investigators, the EEOC is responsible for enforcing ADA Title I. The EEOC has the authority to conduct investi- gations, recommend mediation, attempt conciliation, and/or pursue litigation if to resolve charges [51]. When a complaint is filed with the EEOC, it is reviewed to confirm EEOC jurisdiction, that the employer is a covered entity, and that the complaint includes the information required to evaluate the allegation [52].

Under an Interagency Personnel Agreement (IPA) involving the EEOC, the Director of NEARP began a nationwide project in 2003 to utilize the secondary level data from the EEOC IMS database for research purposes. NEARP proceeded to extract and refine the IMS database in order to retrieve, verify, and examine closed ADA allegations. Permissions were secured by IRB consent at participating institutions as well as supervision by the EEOC Department of Research to maximize proper research conduct regarding confidentiality and data security. Specific extraction protocols were followed to prepare the study dataset for analysis. Following are the relevant parameters considered during transfer of data from the EEOC Integrated Mission System to the NEARP study dataset.

- The unit of study is an allegation. A Charging Party may file more than one allegation (e.g., involving both wages and promotion), or may file allegations on more than one occasion.

- Study data are strictly limited to allegations brought under Title I of the ADA. Other federal employment statutes including the Rehabilitation Act of 1973, Civil Rights Act, Equal Pay Act, or Age Discrimination in Employment Act are not studied by NEARP.

- Only allegations received, investigated, and closed by the EEOC are included.

- Excluded from this study are all allegations which:

1. are investigated by non-EEOC personnel only, typically employed by state Fair Employment Practices agencies;

2. are referred by EEOC to be resolved in civil court,

3. involve the issue of Retaliation because this issue does not pertain directly to the existence or consequence of disability;

4. involve elements which do not directly address the research questions for this study; or

5. involve impairment groupings other than hearing or those not involving known physical or neurological impairments 


\subsection{Study design}

The NEARP team implemented an ex post facto, causal comparative quantitative design that included both descriptive statistics and odds ratios. The overarching purpose of the study was to gain a thorough understanding of workplace discrimination experiences of Americans with deafness and loss of hearing (Hearing) when compared to a general disability population (GENDIS). GENDIS included 22 codes of known physical or neurological conditions. These impairments were chosen to represent non-behavioral conditions involving a physical basis with minimal psychiatric or other sensory overlays. GENDIS cohorts included Pre-Amendment data (1992-2008, $N=195,279$ closed allegations) and Post-Amendment data (2009-2016, N = 144,516 closed allegations). The average increase in allegations annually from approximately 12,200 to over 18,000 may be considered evidence of the overall impact of the amendment, broadly extending coverage to Charging Parties in the post ADAAA era.

The Hearing cohort data file does not distinguish between deafness and hearing loss.. However, the EEOC defines deafness as the inability to hear and understand normal conversational speech through the unaided ear alone (usually a loss of 90 decibels or greater). Hearing loss involves a drop of 27 to 70 decibels and some ability to hear, with or without a hearing aid. The Hearing cohort includes PreAmendment data $(\mathrm{N}=12,433$ closed allegations $)$ and Post-Amendment data ( $\mathrm{N}=9,414$ closed allegations). The lower frequencies Post-Amendment are due in part to a disparate number of calendar years (16 vs. 8 ) in the respective reporting periods as well of the impact of the Great Recession, 2007-2012.

The specific variables of interest for this study involve both target (Hearing) and comparison (GENDIS) groups as well as three distinct factors for each including:

- Demographic Characteristics of the Charging Parties: Gender, Age, and Race/Ethnicity.

- Nature of the Discrimination Alleged, or Issue: Codes for 40 distinct personnel actions which may be linked to discrimination if executed unlawfully according to EEOC criteria.

- Merit Status of the Closed Investigation: Conclusion by EEOC of whether or not the investigation resulted in a finding of Merit (settlement or clear evidence of likely discrim- ination) or Non-Merit (insufficient evidence or closure due to technicality).

\subsection{Statistical analysis}

For Characteristics of Charging Parties (gender, age, and race/ethnicity) and Merit status, descriptive statistics suffice to describe our populations. This is true because this study contains every reported ADA allegation of workplace discrimination which meets the extraction criteria. These are population statistics, not samples.

For the examination of Issues and Merit resolutions, simple proportions and odds ratios are used to examine the relationships between Hearing and GENDIS in terms of frequencies expected and observed. In terms of analysis, the comparison group (the GENDIS group) establishes all "frequencies and proportions expected." The Hearing loss group contributes the "frequencies and proportions observed" which defines its unique nature and scope, if any.

\section{Findings and discussion by variable of interest}

\subsection{Variable one: Characteristics of the charging parties}

Charging parties (Charging Parties) are those individuals with disabilities who filed one or more allegations of workplace discrimination with the EEOC. Besides the nature of impairments, data were recorded for Charging Parties regarding sex, age, and ethnicity (Table 1). Prominent changes occurred for both the GENDIS and Hearing groups following onset of the Post-2008 Amendments period from 2009 to 2016 inclusive. The reader is reminded that the unit of analysis is the allegation, not the Charging Party or Employer. As such, all frequencies which follow in this section refer to the number of allegations derived from a specific grouping of Charging Parties.

First the shift in the gender composition of Charging Parties is addressed. In the Pre-2008 Amendments period, allegations in both groups originated overwhelmingly with male Charging Parties. In GENDIS there was $a+5.2 \%$ gap favoring males. In Hearing there was $a+13.4 \%$ gap favoring males. In the Post2008 Amendments period, however, there were more females who were the subjects of the allegations. In GENDIS there was then $a+11.8$ gap favoring 
Table 1

Cohort Group Sizes and Demographic Characteristics of Charging Parties

\begin{tabular}{|c|c|c|c|c|}
\hline \multicolumn{5}{|c|}{ GENDIS $(339,795)$ vs. Hearing $(21,874)$} \\
\hline \multirow{4}{*}{ N Allegations } & \multicolumn{2}{|c|}{ Pre-2008 Amendments } & \multicolumn{2}{|c|}{ Post-2008 Amendments } \\
\hline & GENDIS & Hearing & GENDIS & Hearing \\
\hline & 195,279 & 12,433 & 144,516 & 9,414 \\
\hline & Proportion & Proportion & Proportion & Proportion \\
\hline \multicolumn{5}{|l|}{$\overline{\text { Gender }}$} \\
\hline Female & $47.4 \%$ & $43.3 \%$ & $55.9 \%$ & $54.2 \%$ \\
\hline Male & $52.6 \%$ & $56.7 \%$ & $44.1 \%$ & $45.8 \%$ \\
\hline Median Age: & $45 y r$ & $43 \mathrm{yr}$ & $46 \mathrm{yr}$ & $49 \mathrm{yr}$ \\
\hline \multicolumn{5}{|l|}{ Race/Ethnicity } \\
\hline AfAmer & $21.4 \%$ & $13.2 \%$ & $31.5 \%$ & $19.7 \%$ \\
\hline As/Hx/NA & $10.2 \%$ & $10.6 \%$ & $7.5 \%$ & $8.8 \%$ \\
\hline Other & $6.6 \%$ & $7.0 \%$ & $0.0 \%$ & $0.0 \%$ \\
\hline White & $61.8 \%$ & $69.3 \%$ & $60.9 \%$ & $71.5 \%$ \\
\hline
\end{tabular}

females. Likewise, in Hearing, there was $a+11.6$ gap favoring females. This gender difference was noted and interpreted by Bowe et al. [40] It is possible that this observation derives from the fact that beginning with the effective date of 2008 Amendments on January 1, 2008, the US economy was in the Great Recession which ran from 2007 through 2012. After the 2008 Amendments, the male and disabled share of allegations declined, whether GENDIS or Hearing. One hypothesis is that job loss during the recession was largely concentrated among men with more females were retained at work and available to file charges. McMahon et al. [48] have documented these trends copiously and they provide ample evidence of the "He-cession" and the deleterious consequences to workers with disabilities. The magnitude of adverse impact on persons with disabilities were computed as roughly $50 \%$ more severe including unemployment, labor force participation, and employment-to-population ratio. The range of median ages is more compressed for GENDIS (45-46 years) than Hearing (43-49 years), and the Hearing group age has increased more in both the within group proportion of total allegations as well as age of the Charging Party.

\subsection{Variable two: Discrimination issues and their five factors}

Issues describe the nature or essence of the allegation itself. Issues involve 42 discrete personnel actions (codes) that by law should be unrelated to the existence or consequence of disability. In the interest of parsimony for this study, only those issues are reported which (when grouped for similarity) represent at least $5 \%$ of all allegation activity. Of the 42 ,
16 are combined into five high volume and related issue categories which account for between $79.7 \%$ and $83.6 \%$ of all allegation activity. The five allegation issues are Discharge and Constructive Discharge, Failure to Reasonably Accommodate, Terms and Conditions of Employment, Disability Harassment and Intimidation, and Hiring and Related. Findings are reported as two tables:

- Table 2 represents the targeted Hearing loss group, divided into Pre- and Post-Amendment Conditions.

- Table 3 represents the comparison GENDIS group, divided into Pre- and Post-Amendment Conditions.

In terms of analysis, the GENDIS group establishes all "frequencies and proportions expected" in terms of its contribution to Chi-squared. The Hearing loss group contributes the "frequencies and proportions observed" which defines its unique nature and scope.

Because of the collective prevalence of these five "mega issues," ADA-literate employers, advocates, and researchers prioritize these particular personnel actions. The reader may note that the overwhelming majority of discriminatory allegations are related to job retention or the quality of work, and are not hiring related [53, 54].

For ease of comparison these two tables are carefully placed one above the other. In making visual comparisons, it is important to note not just the size but the direction of all proportions. The proportions are much more important than the frequencies (Column C), because they constitute a valid basis for comparisons of groups which are very different in the ranges of their frequencies (Tables 2 and 3). Also important are the odds ratios (Column D) which 
Table 2

Hearing Issue Allegations Pre- vs. Post-2008 Amendments

\begin{tabular}{|c|c|c|c|c|}
\hline Issue(s) & $\begin{array}{c}\text { A. Pre } \\
\text { Hearing N/ } \\
\text { Proportion } \\
12,433100 \%\end{array}$ & $\begin{array}{c}\text { B. Post } \\
\text { Hearing N/ } \\
\text { Proportion } \\
9,414100 \%\end{array}$ & $\begin{array}{l}\text { C. Change In } \\
\text { Magnitude } \\
\text { Pre-vs. } \\
\text { Post }\end{array}$ & $\begin{array}{c}\text { D. ODDS RATIOS: } \\
\text { Value of } \% \text { Change } \\
\text { Pre vs. } \\
\text { Post }\end{array}$ \\
\hline Firing + Constructive Discharge (2 Codes) & $340627.4 \%$ & $252626.8 \%$ & $-0.6 \%$ & $1.0 /+0.98$ \\
\hline Reasonable Accommodation (1 Code) & $224218.0 \%$ & $196420.8 \%$ & $+2.8 \%$ & $1.0 /+1.15$ \\
\hline Hiring + Related (10 Codes) & $196915.8 \%$ & $117212.4 \%$ & $-3.4 \%$ & $1.0 /+0.79$ \\
\hline Harassment + Intimidation (2 Codes) & $129110.4 \%$ & $123513.1 \%$ & $+2.7 \%$ & $1.0 /+1.26$ \\
\hline Terms/Conditions (1 Code) & $11259.0 \%$ & $97010.3 \%$ & $+1.3 \%$ & $1.0 /+1.14$ \\
\hline 5 Major Issues (16 Codes) & $10,00380.6 \%$ & $786783.6 \%$ & $+3.0 \%$ & $1.0 /+1.04$ \\
\hline Other Small Issues (26 Codes) & $2,43019.4 \%$ & $1,54716.4 \%$ & $-3.0 \%$ & $1.0 /+0.85$ \\
\hline Total (42 Codes) & $12,433100 \%$ & $9,414100 \%$ & & \\
\hline
\end{tabular}

Table 3

GENDIS Issue Allegations Pre- vs. Post-2008 Amendments

\begin{tabular}{|c|c|c|c|c|}
\hline Issue(s) & $\begin{array}{c}\text { A. Pre } \\
\text { GENDIS N/ } \\
\text { Proportion } \\
195,279100 \%\end{array}$ & $\begin{array}{c}\text { B. Post } \\
\text { GENDIS N/ } \\
\text { Proportion } \\
144,516100 \%\end{array}$ & $\begin{array}{l}\text { C. Change in } \\
\text { Magnitude } \\
\text { Pre vs. } \\
\text { Post }\end{array}$ & $\begin{array}{c}\text { D. ODDS RATIOS: } \\
\text { Value of } \% \text { Change } \\
\text { Pre vs. } \\
\text { Post }\end{array}$ \\
\hline Firing + Constructive Discharge (2 Codes) & $66,70034.2 \%$ & $47,96433.1 \%$ & $-1.1 \%$ & $1.0 /+0.97$ \\
\hline Reasonable Accommodation ( 1 code) & $41,68721.3 \%$ & $33,02322.9 \%$ & $+1.6 \%$ & $1.0 /+1.08$ \\
\hline Hiring + Related (10 Codes) & $16,4088.4 \%$ & $14,76810.2 \%$ & $+1.8 \%$ & $1.0 /+1.21$ \\
\hline Harassment + Intimidation (2 Codes) & $16,0528.2 \%$ & $14,52310.0 \%$ & $+1.8 \%$ & $1.0 /+1.22$ \\
\hline Terms/Conditions $(1$ code $)$ & $14,9137.6 \%$ & $9,0396.3 \%$ & $-1.3 \% 1$ & $1.0 /+0.83$ \\
\hline 5 Major Issues (16 Codes) & $155,76079.7 \%$ & $119,31782.5 \%$ & $+2.8 \%$ & $1.0 /+1.04$ \\
\hline Other Small Issues (26 Codes) & $39,51920.3 \%$ & $25,19917.4 \%$ & $-2.9 \%$ & $1.0 /+0.86$ \\
\hline Total (42 Codes) & $195,279100 \%$ & $144,516100 \%$ & & \\
\hline
\end{tabular}

allow for a ready comparison of the magnitude and direction of the proportional change Pre-and PostAmendments.

As in all NEARP publications to date, the most frequently filed allegation issue is Discharge/Constructive Discharge. The heavy consequences of this action both to employers and workers exceeds that of any other issue. It involves a separation of the employer-worker bond, and causes emotional and economic costs to both parties. Pure Discharge (92.6\% of this variable) is defined by EEOC as involuntary termination of employment status on a permanent basis. Constructive discharge constitutes only $7.4 \%$ of the combined category. Constructive Discharge involves a collusion among managers to force the employee to resign due to discriminatory restrictions, constraints or intolerable working conditions. Matters are exacerbated when the Charging Party has functional limitations affecting communication, as documented in the aforementioned literature.

Firing issues derived from GENDIS were not significantly different in the Post-2008 Amendments condition $(-1.1 \%)$. Hearing had an even smaller decrease of $-0.6 \%$. The odds ratios were extremely even at 1.0 to 0.97 and 1.0 to 0.98 respectively. This metric indicates that for every 100 firing related allegations in each group Pre-Amendments, there were only 2 or 3 fewer afterward, a virtual tie. However, when comparing the same rows from Tables 2 and 3 , it becomes clear that GENDIS (33 to $34 \%$ range) consistently receives a much higher proportion of firing related allegations than Hearing (16 to $21 \%$ range) across both time periods. This signals a significant advantage for Hearing Charging Parties in terms of both higher job retention and lower levels of disciplinary problems.

The second most common allegation for all impairment groups is the Failure to Provide Reasonable Accommodation for a functional limitation. ADA is the only federal employment law that requires a duty to accommodate. Here again we notice what seem like similar increases Pre- to Post-Amendments for both groups. But the odds ratios expose a large difference. For every 100 accommodation allegations Pre-Amendments, the GENDIS group experienced 108 Post-Amendments. The Hearing group, however experienced 115, almost doubling directional difference. Comparing rows from Table 2 to Table 3, the GENDIS (21 to $23 \%$ range) group was consistently higher than Hearing in both time periods, indicating Hearing (18 to $21 \%$ range) had a lower level of 
difficulty than the GENDIS with respect to accommodations. Perhaps in part this is due to the narrower range of accommodation needs (interpreters and text to speech technologies) compared a broader broad range of accommodation needs for GENDIS. Additionally, this may reflect the fact that Title IV of ADA (and related legislation) required substantially more costly investments by businesses and governments in the removal of communication barriers, technological innovation, accommodation, and investment which primarily benefitted workers with sensory impairments [55].

Next we examine the issues of Hiring and Related allegations. EEOC defines a hiring as failure or refusal by an employer to engage a person as an employee. Pure hiring is $79 \%$ of this category and "related" includes the balance of $21 \%$ including (in order of proportion) job assignment, prohibited medical inquiry, training access, recall from layoff, segregated unions or facilities, qualification standards, testing, and access to apprenticeships. Allegations of Hiring and Related GENDIS and Hearing proportions changed in opposite directions following the Amendments, with a rise of $+1.8 \%$ for GENDIS and a decline of $-3.4 \%$ for Hearing. The odds ratios tell the story again, with a rise of 21 per 100 allegations by GENDIS and a near equal decline of 21 per 100 by Hearing. Comparing these rows from Table 2 to Table 3, we see again that despite these large changes in Pre- and Post-Amendment direction, Hiring has been consistently more problematic for Hearing (12 to $16 \%$ range) than GENDIS (8 to $10 \%$ range), although the differences are narrowing. The picture suggests a somewhat greater level of employer comfort for hiring GENDIS (despite greater discomfort for GENDIS accommodations).

Next is the issue of disability Harassment and Intimidation. The basic definition of both terms as used EEOC is the same as for sex discrimination; i.e. bothering, tormenting, troubling, ridiculing, intimidating, antagonizing or coercing a person on the basis of (disability, gender, race, religion, etc.). The basis for the allegation for NEARP is the existence or consequence of disability. The nuances of difference between Harassment and Intimidation involves the locus of the alleged offense. Harassment is about $87 \%$ of the combined group and typically occurs in non-employment settings. Intimidation is the balance of $23 \%$. Unfortunately, both GENDIS and Hearing groups experienced Post-Amendment increases of $+1.8 \%$ and $+2.7 \%$ respectively. The odds ratios show whopping increases of 1.0/+1.22 for GENDIS and 1.0/+1.26 for Hearing. This may be attributed to the societal shift in the intolerance for and coverage of harassment for all protected classes which is extended to training, attitudes, policies, laws, regulations, and all aspects of career, education, socialization, disclosure, and journalistic reporting. Comparing Tables 2 and 3, the Hearing group is disproportionately affected by this issue both before and after the Amendments. Shaw et al. [56] have documented that the impairment groups with the highest levels of merit resolutions for this issue are deafness, intellectual disability and traumatic brain injury. The authors highlight the coincidence that major functional limitations for all three impairments involve comprehension and communication. They conclude that this makes Harassment all the more insidious as an unlawful personnel action matter.

Finally, there is the large and ubiquitous issue of Terms and Conditions of employment. This is defined by EEOC as denial or inequitable application of rules relating to general working conditions, job environment, or employment privileges which cannot be reduced to monetary value. Examples include: assignment to unpleasant work stations; failure to provide adequate tools or supplies; inequities in shift assignments or vacation preferences; or restriction as to mode of dress or appearance. These are squarely related to working conditions, and GENDIS and Hearing moved in opposite directions following the Amendments, with a decline of $-1.3 \%$ for GENDIS and a rise of $+1.3 \%$ for Hearing. The corresponding odds ratios show 1.0/+0.83 for GENDIS and 1.0/+1.14 for Hearing, substantial movement albeit in opposite directions. A comparison of rows indicates this has been a much higher area of allegation activity during both time periods for Hearing ( 9 to $10 \%$ range v. 6 to $8 \%$ for Gendis), and the gap has really expanded even more in the Post-Amendments era. These tiny issues are all matters of job satisfaction and the quality of work life. However, due to the diversity and ubiquity of this particular issue, there is no clear explanation of this finding.

Both tables above reference 26 additional issues which are not included here due to proportion sizes less than $5 \%$. In fact, 25 of these are less than $3 \%$. Although interesting, these proportions are much less reliable and rarely actionable and as such are beyond the scope of this manuscript. As a practical matter, workplace discrimination would be greatly mitigated by an initial focus on the aforementioned personnel issues and a better utilization of EEOC resources in general. 
Table 4

Hearing Merit Closure Allegations: Pre- vs. Post-2008 Amendments

\begin{tabular}{llcccc}
\hline Merit Yes/No & Outcome & $\begin{array}{c}\text { Pre Hearing N/ } \\
\text { Proportion } \\
12,433100 \%\end{array}$ & $\begin{array}{c}\text { Post Hearing N/ } \\
\text { Proportion }\end{array}$ & $\begin{array}{c}\text { Change magnitude } \\
\text { Pre vs. } \\
\text { Post }\end{array}$ & $\begin{array}{c}\text { Relative value } \\
\text { of Change } \\
\text { Pre vs. Post }\end{array}$ \\
\hline Y & & $198115.9 \%$ & $1950^{*} 20.7 \%$ & $+4.8 \%$ & $1.0 /+1.30$ \\
Y & Settle w/Benefits & $141711.4 \%$ & $521 * 5.5 \%$ & $-5.9 \%$ & $1.0 /+0.49$ \\
Total Merit $\%$ & EEOC finds Merit & $\mathbf{2 7 . 3 \%}$ & $\mathbf{2 6 . 2 \%}$ & $\mathbf{- 1 . 1 \%}$ & $\mathbf{1 . 0 / + 0 . 9 6}$ \\
N & & $792363.7 \%$ & $635367.5 \%$ & $+3.8 \%$ & $1.0 /+1.06$ \\
N & EEOC finds No Merit & $11128.9 \%$ & $5906.3 \%$ & $-2.6 \%$ & $1.0 /+0.71$ \\
Tot Non-Merit\% & Administrative Technical & $\mathbf{7 2 . 6 \%}$ & $\mathbf{7 3 . 8 \%}$ & $\mathbf{+ 1 . 2 \%}$ & $\mathbf{1 . 0 / + 1 . 0 2}$ \\
TOTAL & & $\mathbf{1 2 , 4 3 3 9 9 \%}$ & $\mathbf{9 , 4 1 4 ~ 1 0 0 \%}$ & & \\
\hline
\end{tabular}

Table 5

GENDIS Merit Closure Allegations: Pre- and Post-2008 Amendments

\begin{tabular}{llcccc}
\hline Merit Yes/No & Outcome & $\begin{array}{c}\text { Pre GENDIS N/ } \\
\text { Proportion } \\
195,279100 \%\end{array}$ & $\begin{array}{c}\text { Post GENDIS N/ } \\
\text { Proportion } \\
144,516100 \%\end{array}$ & $\begin{array}{c}\text { Change magnitude } \\
\text { Pre vs. } \\
\text { Post }\end{array}$ & $\begin{array}{c}\text { Relative value } \\
\text { of Change } \\
\text { Pre vs. Post }\end{array}$ \\
\hline Y & Settle w/Benefits & $29,76715.2 \%$ & $29,84920.7 \%$ & $+5.5 \%$ & $1.0 /+1.36$ \\
Y & EEOC finds Merit & $13,9957.2 \%$ & $6,9274.8 \%$ & $-2.4 \%$ & $1.0 /+0.67$ \\
Total Merit $\%$ & & $\mathbf{2 2 . 4 \%}$ & $\mathbf{2 6 . 4 \%}$ & $\mathbf{+ 4 . 0 \%}$ & $\mathbf{1 . 0 / + 1 . 1 7}$ \\
N & EEOC finds No Merit & $129,88166.5 \%$ & $99,41368.8 \%$ & $+2.3 \%$ & $1.0 /+1.04$ \\
N & Administrative Technical & $21,63611.1 \%$ & $8,3275.8 \%$ & $-5.3 \%$ & $1.0 /+0.53$ \\
Tot Non- Merit \% & & $\mathbf{7 7 . 6 \%}$ & $\mathbf{7 4 . 6 \%}$ & $\mathbf{- 3 . 0 \%}$ & $\mathbf{1 . 0 / + 0 . 9 7}$ \\
TOTAL & & $\mathbf{1 9 5 , 2 7 9 ~ 1 0 0 \%}$ & $\mathbf{1 4 4 , 5 1 6 ~ 1 0 0 \%}$ & & \\
\hline
\end{tabular}

\subsection{Variable three. Outcomes of EEOC investigations and two factors. Merit and non-merit}

Few variables are as important as the outcome of the EEOC investigations. These reveal the closure status, disposition, or outcome of all EEOC investigations as the case is closed. NEARP sorts these closures into three major categories. Merit closures favor the Charging Parties. They signal that the allegation is upheld, and that both sides either reached a settlement involving benefits to the Charging Party, or the EEOC concluded that discrimination likely did occur and the employer acted unlawfully. If we think of all closure studies in all NEARP findings, Merit resolutions generally hover around $24 \%$ of all closures [57]. The Merit closure finds that the allegation was not merely a Charging Party's perception of discrimination. Rather, the allegation constituted an actual discriminatory event and as such was meritorious.

By default, then, Non-merit closures are a form of employer vindication. They have two general groupings. First, "No cause" findings indicate that a thorough investigation by EEOC has failed to produce evidence that rises to the level of discrimination. These are bountiful and tend to hover around $66 \%$ of all closed allegations for all studies. They suggest that employers are reasonably well defended, partic- ularly with regard to discharge [58]. The second form of Non-merit closure is less stable, ranging from 5\% to $21 \%$ of all closed allegations for all studies. These include nine types of technicalities or administrative complications resulting in a closed case. Examples include EEOC lack of jurisdiction, employer bankruptcy, uncooperative or non-responsive Charging Parties, or claim processing problems. These are regarded by NEARP as favoring the employer in that evidence of Merit cannot be determined. These are resolved as Administrative closures without merit.

With respect to the present study, we see in Tables 4 and 5 that Post-Amendment the GENDIS group advanced by $+4.0 \%$ points in the Total Merit category, resulting in an odds ratio of $1.0 /+1.18$, a substantial Post-Amendments increase. This demonstrates that GENDIS was filing allegations with more veracity (i.e., complaints found to be valid or true), and the Amendments were working in their favor. In contrast, the Hearing group declined in Total Merit by $1.1 \%$, resulting in an odds ratio of 1.0/+0.96, a small drop. This is a small decline but shows that Hearing allegations may have had less veracity, and there was no advantage derived from the Amendments. However, comparing the rows in Tables 4 and 5, we observe that the Hearing group had a much higher Merit rate than GENDIS Pre-Amendments (27.3\% vs. $22.4 \%$ ), then dipped into a virtual tie Post-Amendments by $-0.2 \%$. As it stands presently, both groups are slightly 
above average compared to the entire database with replacement (i.e., including hearing allegations).

Equally important are increases in the pure No Merit subcategory ("no reasonable cause after EEOC investigation") for both GENDIS (+2.3\%) and Hearing $(+3.8 \%)$. The odds ratios for these changes were $1.0 /+1.04$ and 1.0/+1.06 respectively. Surprisingly, these modest increases represent increases in employer victories upon case closure, and as such they suggest that the Amendments were well understood by the employers and they adapted and were well defended legally. Indeed, in terms of implementations of the Amendments, employers have done better despite a preponderance of legal aspects which favored the Charging Parties in the new statute itself.

Conversely, there were precipitous declines in Administrative closures for both groups, with large drops in relative value, particularly for GENDIS $(-47.7 \%)$. This is good news or both Charging Parties and employers. The larger declines appeared in sub-categories including Charging Party non-responsiveness, uncooperativeness, or disappearance. EEOC also reduced jurisdictional and processing problems following the procedural changes required by the Amendments. Given the general confusion of drafting new regulations (caused by the Amendments) and the substantial negative impacts of the Great Recession (2007 to 2012), it is probably not prudent to attempt to interpret the administrative closures too extensively.

In brief, Merit rates for both groups continued to be elevated for Hearing when compared to other large GENDIS groups, but the gap is closing between groups. On the Non-Merit side, employers are prevailing more frequently, probably due in part to the increased attention paid to ADA in general over time and resulting from the impact of the Amendments. Employees also appear to be more persistent in adhering to the investigatory process as evidenced by the decline in Administrative closures and their specific nature.

\section{Conclusion}

The present findings indicate that allegations involving Hearing loss have a number of unique features when compared to those involving a general disability group consisting of physical and neurological impairments. Different disability groups experience workplace discrimination differently. Particular contrasts (both positive and negative) can inform us how these groups experience workplace discrimination differently. This has long been a serious inquiry by NEARP and is not intended to obstruct or compromise the importance of the cross-disability movement. But facts are stubborn things, and these particular facts are known about the uniqueness of the Hearing loss allegations:

- Males were dominant in allegation activity for both groups prior to the Amendments. Both groups flipped, with females inheriting the dominant position by wide margins PostAmendments.

- Whereas median ages were stable and consistent with other studies, the median age of Hearing Charging parties soared from 43 to 49 years PostAmendments.

- Both groups increased African American activity levels Post-Amendments, but GENDIS representation was markedly higher in both time periods (21.4\% and $31.5 \%)$ GENDIS vs. (13.2\% and $19.7 \%$ ) Hearing.

- GENDIS maintains a historical lead in the proportion of Reasonable Accommodation allegation activity. Both increased Post-Amendments, with Hearing experiencing greater momentum toward parity GENDIS $+1.6 \%$ vs. Hearing $+2.8 \%$.

- Hearing maintains a historical lead in the proportion of Hiring and Related allegation activity. Post-Amendments, Hearing declined $-3.4 \%$ while GENDIS increased $+1.8 \%$, but the gap persists and in turn it continues to be more difficult to access the workforce for the Hearing population.

- Harassment and Intimidation allegations increased dramatically for both groups, but more so for Hearing than GENDIS ( $+2.7 \%$ vs. $+1.8 \%$ ). The national focus to these issues led by women has likely expanded to all protected classes.

- The Merit closure rate (indicating the veracity of allegations) improved+4\% for GENDIS and declined $-1.1 \%$ for Hearing in the PostAmendment era. These outcome decisions favor Charging Parties. There were strong gains for settlement activity in both groups.

- The Non-merit closure rate (favoring employers) decreased $-3 \%$ for GENDIS while increasing $+1.2 \%$ for Hearing. In both groups there were increases for "insufficient cause" at the end of extensive EEOC investigations. Administrative 
closures are dissipated across the board. Despite the Amendments, employers are well defended on the high prevalence issues.

The specifics of these differences offer a worthwhile pursuit for future researchers from NEARP and elsewhere, perhaps using more qualitative measures. Future research questions may include (a) what is driving the inordinately high rate of hiring discrimination for individuals with Hearing impairment, (b) what is influencing higher rates of harassment/intimidation discrimination for individuals from both groups, and (c) how do ADA literacy rates compare for employers vs. persons with disabilities and their advocacy organizations?

There are also political aspects to studies such as these. Does our disability-specific reporting obstruct the goals of the cross-disability movement in the U.S.? This movement proposes to deliver a collective voice in advocating persons with disabilities. Leading organizations, such as the National Disability Leadership Alliance (2018), work to shape national policies, politics, media, and culture [59]. Advocacy involves various political actions and sometimes these actions need to be tailored depending on issues and problems that specific groups experience in the workforce. Further, delving deeper into the discrimination experience by disability type is not only appropriate but necessary. We have learned not to assume that the disability experience is the same regardless of type and severity of disability, but on the other hand it is also important to deliver a collective voice in actively advocating for the employment rights of all persons with disabilities.

\section{Conflict of interest}

None to report.

\section{References}

[1] US Equal Employment Opportunity Commission (EEOC). Jim Walter Resources Coal Company discriminated against deaf mineworker [Press release]. 2009 Sep 25.

[2] US Equal Employment Opportunity Commission (EEOC). PETCO to pay $\$ 145,000$ for failing to accommodate deaf pet groomer [Press release]. 2010 Jun 29.

[3] US Equal Employment Opportunity Commission (EEOC). EEOC sues Haven Manor for refusing to accept hearingimpaired certified nursing assistant [Press release]. 2010 Jun 3.

[4] US Equal Employment Opportunity Commission (EEOC). Questions and answers about deafness and hearing impairments in the workplace and the Americans with Disabilities Act [Internet]. [cited 2019 Jun 26]. Available from: https://www1.eeoc.gov//eeoc/publications/qa_deafness.cfm ?renderforprint $=1$.

[5] DeafTEC. For employers: Resources for hiring and integration: Deaf and hard-of-hearing: Some definitions [Internet]. Rochester Institute of Technology, National Technical Institute for the Deaf. Available from: https://www.deaftec.org/content/deaf-definitions.

[6] Zelaya CE, Lucas JW, Hoffman HJ. Self-reported hearing trouble in adults aged 18 and over: United States, 2014. US Department of Health and Human Services, Centers for Disease Control and ...; 2015.

[7] Brault MW. Current population reports. Americans with Disabilities: 2005. Household economic studies. Washington, DC; 2008.

[8] World Health Organization. Deafness and hearing loss: Fact sheet [Internet]. 2018 [cited 2019 Jun 26]. Available from: http://www.who.int/mediacentre/factsheets/fs300/en/.

[9] Watson D, Adams T, Fish T, Latz R, Boone S. Model state plan for vocational rehabilitation services to persons who are deaf, deaf-blind, hard of hearing, or late deafened. University of Arkansas Rehabilitation Research and Training Center; 2008.

[10] Leigh I. A lens on deaf identities. Perspectives on Deafness; 2009.

[11] Lane H. Do deaf people have a disability? Sign Lang Stud. 2002;2(4):356-79.

[12] Mason DG. Quality of life for deaf and hard-of-hearing people. In: Renwick R, Brown I, Nagler M, editors. Quality of life in health promotion and rehabilitation: Conceptual approaches, issues, and applications. Thousand Oaks, CA: Sage Publications, Inc; 1996. p. 237-252.

[13] Luey HS, Glass L, Elliott H. Hard-of-hearing or deaf: Issues of ears, language, culture, and identity. Soc Work. 1995;40(2):177-82.

[14] David M, Trehub SE. Perspectives on Deafened Adults. Am Ann Deaf. 1989;134(3):200-4.

[15] Luey HS. Between worlds: The problems of deafened adults. Soc Work Health Care. 1980;5(3):253-65.

[16] Rutman D. The impact and experience of adventitious deafness. Am Ann Deaf. 1989;134(5):305-11.

[17] Luft P. Communication barriers for deaf employees: Needs assessment and problem-solving strategies. Work. 2000;14(1):51-9.

[18] Falvo D, Holland BE. Medical and psychosocial aspects of chronic illness and disability. Jones \& Bartlett Learning; 2017.

[19] Israelite N, Ower J, Goldstein G. Hard-of-Hearing Adolescents and Identity Construction: Influences of School Experiences, Peers, and Teachers. J Deaf Stud Deaf Educ. 2002;7(2):134-48.

[20] DeBonis DA, Donohue CL. Survey of audiology: Fundamentals for audiologists and health professionals. Allyn \& Bacon; 2003.

[21] Erickson W, Lee C, Von Schrader S. Disability statistics from the 2017 American Community Survey (ACS). Ithaca, NY; 2017.

[22] Sanford C, Newman L, Wagner M, Cameto R, Knokey AM, Shaver D. The Post-High School Outcomes of Young Adults with Disabilities up to 6 Years after High School. Key Findings from the National Longitudinal Transition Study2 (NLTS2) National Center for Special Education Research (NCSER 2011-3004). Menlo Park, CA: SRI International; 2011. 
[23] Carnevale AP, Desrochers DM. Standards for what?: The economic roots of K-16 reform. Communication and Public Affairs, Office of Assessment, Equity, and Careers ...; 2003.

[24] Punch R. Employment and adults who are deaf or hard of hearing: Current status and experiences of barriers, accommodations, and stress in the workplace. Am Ann Deaf. 2016;161(3):384-97.

[25] Capella ME. Comparing Employment Outcomes of Vocational Rehabilitation Consumers with Hearing Loss to Other Consumers and the General Labor Force. Rehabil Couns Bull. 2003 Oct 13;47(1):24-33.

[26] Houston K, Lammers HB, Svorny S. Perceptions of the Effect of Public Policy on Employment Opportunities for Individuals Who Are Deaf or Hard of Hearing. J Disabil Policy Stud. 2010 Jun 3;21(1):9-21.

[27] Boutin DL, Wilson KB. Professional Jobs and Hearing Loss: A Comparison of Deaf and Hard of Hearing Consumers. J Rehabil. 2009;75(1):36-40.

[28] Boutin DL. Occupational Outcomes for Vocational Rehabilitation Consumers with Hearing Impairments. J Rehabil. 2010;76(3):40-6.

[29] Bureau of Labor Statistics. 2010 Standard Occupational Classification System. 2010.

[30] Bureau of Labor Statistics. 2018 Standard Occupational Classification Manual. 2018.

[31] Bolin JH. Hayes, Andrew F. (2013). Introduction to Mediation, Moderation, and Conditional Process Analysis: A Regression-Based Approach. New York, NY: The Guilford Press. J Educ Meas. 2014 Sep 1;51(3):335-7.

[32] Foster S, MacLeod J. Deaf people at work: assessment of communication among deaf and hearing persons in work settings. Int J Audiol. 2003;42 Suppl 1:S128-39.

[33] Geyer PD, Schroedel JG. Conditions influencing the availability of accommodations for workers who are deaf or hard-of-hearing. J Rehabil. 1999;65(2):42-50.

[34] Shuler GK, Mistler LA, Torrey K, Depukat R. More than signing: Communicating with the deaf. Nurs Manage. 2014;45(3):20-7.

[35] Luft P. Employment and Independent Living Skills of Public School High School Deaf Students: Analyses of the Transition Competence Battery Response Patterns. J Am Deaf Rehabil Assoc. 2012;45(3).

[36] Luft P, Huff K. How prepared are transition-age deaf and hard of hearing students for adult living? Results of the Transition Competence Battery. Am Ann Deaf. 2011;155(5):569-79.

[37] Traxler CB. The Stanford Achievement Test: National norming and performance standards for deaf and hardof-hearing students. J Deaf Stud Deaf Educ. 2000;5(4): $337-48$.

[38] Moores DF. Educating the deaf: Psychology, principles, and practices. 4th ed. Boston: Houghton Mifflin; 1996.

[39] Perkins-Dock RE, Battle TR, Edgerton JM, McNeill JN. A Survey of Barriers to Employment for Individuals Who Are Deaf. J Am Deaf Rehabil Assoc. 2015;49(2).

[40] Bowe FG, McMahon BT, Chang T, Louvi I. Workplace discrimination, deafness and hearing impairment: the national EEOC ADA research project. Work. 2005;25(1):19-25.

[41] McCrone WP. Practical Implications of the 2008 Americans with Disabilities Act Amendments (Title I) for Rehabilitation Counselors and Deaf Job Seekers. J Am Deaf Rehabil Assoc. 2011;44(2).
[42] Bruyere SM, Saleh MC. Disability Policy and Law. In: Tarvydas V, Hartley M, editors. The Professional Practice of Rehabilitation Counseling. New York, NY: Springer New York; 2018. p. 95-120.

[43] Rubin SE, Roessler RT, \& Rumrill PD. The Americans with Disabilities Act: Major mandates and ambiguities. In: Rubin S, Roessler R, Rumrill PD, editors. Foundations of the vocational rehabilitation process. 7th ed. Austin, TX: Pro-ed; 2016.

[44] Frierson JG. Heads you Lose, Tails You Lose a Disturbing Judicial Trend in Defining Disability. Labor Law Journal. 1997;48(7):419-430. 45. Rozalski M, Katsiyannis A, Ryan J, Collins T, Stewart A. Americans with disabilities act amendments of 2008. J Disabil Policy Stud. 2010;21(1):22-8.

[45] Feldblum CR, Barry K, Benfer EA. The ADA Amendments Act of 2008 Jacobus tenBroek Law Symposium. Vol. 13, Texas Journal on Civil Liberties \& Civil Rights. 2007. p. 187-99.

[46] Benfer EA. The ADA Amendments Act: An Overview of Recent Changes to the Americans with Disabilities Act. 2010.

[47] Allbright AL. 2007 Employment Decisions under the ADA Title I - Survey Update. Ment Phys Disabil Law Reporter. 2008;32.

[48] McMahon BT. The ADA Amendments Act of 2008: Pocket guide for rehabilitation professionals. Rehabil Couns Prof. 2010;18(1):11-8

[49] McMahon BT. Codebook for Database of the National EEOC ADA Research Project. Richmond, VA: Author; 2017.

[50] US Equal Employment Opportunity Commission (EEOC). Authority and role [Internet]. [cited 2019 Jun 26]. Available from: https://www.eeoc.gov/eeoc/index.cfm.

[51] US Equal Employment Opportunity Commission (EEOC). What you can expect after you file a charge [Internet]. [cited 2019 Jun 26]. Available from: https://www.eeoc. gov/employees/process.cfm.

[52] McMahon, Brian T., and Jessica E. Hurley. "Discrimination in hiring under the Americans with Disabilities Act: An overview of the National EEOC ADA Research Project." Journal of occupational rehabilitation 18.2 (2008): 103-105.

[53] McMahon, Brian T., et al. "Hiring discrimination against people with disabilities under the ADA: Characteristics of charging parties." Journal of Occupational Rehabilitation 18.2 (2008): 122-132.

[54] National Association of the Deaf. Position Statement on Functionally Equivalent Telecommunications for Deaf and Hard of Hearing People. Silver Spring, MD; 2019.

[55] Shaw LR, Chan F, McMahon BT, Kim JH. Employee and employer characteristics associated with elevated risk of filing disability harassment charges. J Vocat Rehabil. 2012;36(3):187-97.

[56] McMahon BT. Codebook for Database of the National EEOC ADA Research Project at VCU. Richmond, VA: Author; 2012

[57] Rumrill Jr PD, Fitzgerald SM. Employer characteristics and discharge-related discrimination against people with disabilities under the Americans with Disabilities Act. Adv Dev Hum Resour. 2010;12(4):448-65.

[58] National Disability Leadership Alliance. Statement from the National Disability Leadership Alliance on Solidarity and the 2016 presidential election. 2018. 